\title{
The reparability of contemporary composite resins
}

\author{
Maria Spyrou ${ }^{1}$, Eugenia Koliniotou-Koumpia ${ }^{1}$, Pantelis Kouros ${ }^{1}$, \\ Elisabeth Koulaouzidou ${ }^{1}$, Pavlos Dionysopoulos ${ }^{1}$
}

Correspondence: Dr. Eugenia Koliniotou-Koumpia

Email: jeny@dent.auth.gr
'Department of Operative Dentistry, Dental School of Aristotle University of Thessaloniki, Thessaloniki, Greece

\section{ABSTRACT}

Objective: The objective was to investigate the way that various surface treatments could influence the bond strength of the repair of methacrylate (MC) and silorane (SIL) composites. Materials and Methods: A total of 160 MC and SIL cylindrical specimens were polymerized and aged in artificial saliva solution for 7 days. Depending on the following surface treatment (diamond bur or air abrasion), and the conditioning procedure (orthophosphoric acid or sodium hypochlorite), 16 groups were formed and repaired either with MC, either with SIL composite. Repaired specimens were subjected to an additional aging procedure in artificial saliva for 7 days, followed by thermo-cycling and then stressed in shear at a rate of $0.5 \mathrm{~mm} / \mathrm{min}$ until failure. Failure patterns were analyzed using stereomicroscope and scanning electron microscopy. Results: MC composite showed statistically significant higher bond strength both as a base or repair material than SIL $(P<0.001)$. Statistically significant differences were not observed, when grinding and conditioning procedures was compared. Pretest failures were observed when aged MC-based composite was repaired with SIL-based. Conclusions: Type of composite seems to be the main factor influencing the bond strength of the repair. MC-based composite showed better repairability than SIL composite. Optimum repair conditions should include knowledge of the composite's composition.

Key words: Bond strength, methacrylate composite, repair, silorane composite, surface treatment

\section{INTRODUCTION}

With the introduction of dental adhesive technology, tooth-colored composite restorations have gained wide popularity in recent decades. Despite innovative improvements over the years, and the long-term stability of composite restorations, failures continue to occur. ${ }^{[1]}$ In cases of failure or fracture of an adhesive restoration, the repair procedure offers a minimally invasive alternative to complete replacement of a restoration. ${ }^{[2]}$ Repair is an alternative to complete removal that preserves the tooth, as it is often difficult to remove an adhesive restoration without removing an integral part of the tooth. ${ }^{[3,4]}$ For all of these reasons, a qualitative, optimal method of repairing composite restorations has become a desirable alternative. ${ }^{[2]}$ The evidence as it currently stands seems to favor repair over replacement, but it is not conclusive. ${ }^{[5]}$
The success of such repairs depends not only on the type of the material used for the initial restoration and the repair procedure utilized, but also on the surface treatment applied to the surface to be repaired. Treating the surface is mandatory, owing to the lack of reactive methacrylate $(\mathrm{MC})$ groups in the old resin, and because the sorption of water by the old restoration restricts the addition of new material. ${ }^{[6]}$ However, the problem for the clinician is that the type and brand of the composite used in the previous restoration is often unknown. The problem is aggravated when different composites with organic matrices other than dimethacrylates have been introduced. Furthermore, various protocols of intraoral repair systems areexploring on the repair potential of indirect aesthetic restorations, ceramic, feldspathic porcelain, and zirconia. ${ }^{[7,8]}$

The repair of MC-based composite restorations is widely considered to be a reliable procedure in

\footnotetext{
How to cite this article: Spyrou M, Koliniotou-Koumpia E, Kouros P, Koulaouzidou E, Dionysopoulos P. The reparability of contemporary composite resins. Eur J Dent 2014;8:353-9.

Copyright $\odot 2014$ Dental Investigations Society.

DOI: $10.4103 / 1305-7456.137647$
} 
modern dentistry. $\cdot^{[9-14]}$ With regard to the repair of silorane (SIL)-based restorations however, too few studies have been reported. ${ }^{[15-19]}$ Moreover, few studies investigating interactions between MC-based composite and SIL-based restorations have been published. ${ }^{[20-24]}$ In addition, studies comparing the bond quality facilitated by different combinations of surface pretreatments (grinding and conditioning) have not been published.

The purpose of this in vitro study was to investigate the influence of different pretreatment proceduresgrinding (by diamond bur [DB] or air abrasion [AA]) and conditioning (orthophosphoric acid [OA] or sodium hypochlorite [HY])-and different organic matrix compositions (MC- and SIL-based composite), on the shear bond strength of repairs to artificial aged composite. The null hypotheses tested were that (a) composites with different organic matrix compositions demonstrate the same reparability, and (b) different surface pretreatment procedures have no influence on the shear bond strength of repaired composites.

\section{MATERIALS AND METHODS}

The following composite systems were tested: The Filtek Ultimate (3M ESPE, St. Paul, MN, USA) (MC), a nanofilled MC-based composite with the corresponding bonding agent Single Bond Adhesive, and the Filtek Silorane (3M ESPE, St. Paul, MN, USA) (SIL), a SIL-based composite with the corresponding bonding agent Silorane Adhesive System. The materials used, and their chemical compositions are listed in Table 1.

Standardized disc-shaped composite substrates of $4 \mathrm{~mm}$ diameter and $2 \mathrm{~mm}$ thickness were prepared for the test specimens, using cylindrical shaped teflon molds with a hole in their center, of those same dimensions. Prior to filling the holes with the resin material, the molds were set on a glass microscope plate in order to achieve a flat surface of the specimen after light-curing. Resin composite was condensate into the hole with a hand instrument, to a thickness of $2 \mathrm{~mm}$, and a second microscope slide was firmly pressed onto the top of the mold to remove excess resin composite, and to create a flat surface. Polymerization of the composite specimens was achieved through the application of a light-emitting diode (LED) polymerisation device for $20 \mathrm{~s}$ (Heraeus Kulzer Translux Power Blue Germany 50/60 Hz $15 \mathrm{VA})$, at a light intensity of $1000 \mathrm{~mW} / \mathrm{cm}^{2}$. Light intensity was periodically verified by a radiometer after the processing of every five specimens (Bluephase meter Ivoclar, Vivadent, Schaan, Liechtenstein). The specimens were then left to age in artificial saliva for 7 days at room temperature. Artificial saliva was prepared according to Donmez et al. ${ }^{[25]}$ and was comprised of the following components $(\mathrm{mmol} / \mathrm{L})$ : $\mathrm{CaCl}_{2} .2 \mathrm{H}_{2} \mathrm{O}(0.7), \mathrm{MgCl}_{2} .6 \mathrm{H}_{2} \mathrm{O}(0.2), \mathrm{KH}_{2} \mathrm{PO}_{4}(4.0)$, $\mathrm{KCl}$ (30.0), HEPES buffer (20.0), $\mathrm{NaN}_{3}$ (3.0). The specimens were then removed from the artificial saliva, air-dried and randomly assigned to the test groups. The chosen combination of surface treatments (grinding procedure and conditioning procedure) for each group was performed. The two types of surface treatment tested were a grinding procedure with the use of a DB (Komet $107 \mu \mathrm{m}$-grit, for $10 \mathrm{~s}$ at high speed with water cooling) (DB) and AA (EMS Air-Flow Prep K1 Max device, 50- $\mu \mathrm{m}$ aluminum oxide for $10 \mathrm{~s}$, with the device set with the nozzle at a distance of $5 \mathrm{~mm}$ ) (AA). In addition, two different conditioning procedures prior to the application of the corresponding bonding agent and the repair composite were compared; application of

\begin{tabular}{|c|c|c|}
\hline Adhesive & $\begin{array}{l}\text { Adper Single } \\
\text { Bond } 2 \text { Adhesive } \\
\text { Lot no. N251345 } \\
\text { (3M ESPE, } \\
\text { St. Paul, MN, USA) }\end{array}$ & $\begin{array}{l}\text { Silorane Adhesive } \\
\text { Lot no. N120915 } \\
\text { (3 M ESPE, St. Paul, MN, USA) }\end{array}$ \\
\hline Composition & $\begin{array}{l}\text { BisGMA, HEMA, } \\
\text { dimethacrylates, } \\
\text { ethanol, water, } \\
\text { photo initiator } \\
\text { system, } \\
\text { methacrylate } \\
\text { functional } \\
\text { copolymer of } \\
\text { polyacrylic and } \\
\text { polyitaconic acids, } \\
\text { silica nanofiller }\end{array}$ & $\begin{array}{l}\text { Primer: Phosphorylated } \\
\text { methacrylates, BisGMA, HEMA, } \\
\text { water, ethanol, silane-treated } \\
\text { silica filler, initiators, stabilizers } \\
\text { Adhesive bond: Hydrophobic } \\
\text { dimethacrylate, phosphorylated } \\
\text { methacrylates, TEGDMA, } \\
\text { silane-treated silica filler, } \\
\text { initiators, stabilizers }\end{array}$ \\
\hline $\begin{array}{l}\text { Resin } \\
\text { composite }\end{array}$ & $\begin{array}{l}\text { Filtek Ultimate A3 } \\
\text { Lot no. N180044 } \\
\text { (3 M ESPE, } \\
\text { St. Paul, MN, USA) }\end{array}$ & $\begin{array}{l}\text { Filtek Silorane A3 } \\
\text { Lot no. N284556 ( } 3 \text { M ESPE, } \\
\text { St. Paul, MN, USA) }\end{array}$ \\
\hline $\begin{array}{l}\text { Resin } \\
\text { matrix } \\
\text { composition }\end{array}$ & $\begin{array}{l}\text { Bis-GMA, UDMA, } \\
\text { TEGDMA, Bis-EMA }\end{array}$ & $\begin{array}{l}\text { 3,4-epoxycyclohexylethylc } \\
\text { yclo-polymethylsiloxane, } \\
\text { bis-3,4-epoxycyclohexylethyl- } \\
\text { phenylmethylsilane } \\
\text { Initiating system: } \\
\text { Camphorquinone, iodonium } \\
\text { salt, electron donor }\end{array}$ \\
\hline $\begin{array}{l}\text { Filler size/ } \\
\text { percentage }\end{array}$ & $\begin{array}{l}20 \mathrm{~nm} \text { silica filler, } \\
4-11 \mathrm{~nm} \text { zirconia } \\
\text { filler, zirconia/silica } \\
\text { cluster filler } \\
78.5 \% \text { by weight }\end{array}$ & $\begin{array}{l}0.1-2.0 \mu \text { m silanized quartz } \\
\text { filler yttrium fluoride, stabilizers, } \\
\text { pigments } \\
76 \% \text { by weight }\end{array}$ \\
\hline \multicolumn{3}{|c|}{$\begin{array}{l}\text { Bis-GMA: Bisphenol-A glycidyl dimethacrylate, HEMA: 2-hydroxyethyl } \\
\text { methacrylate, UDMA: Urethane dimethacrylate, TEGDMA: Triethylene-glycol } \\
\text { dimethacrylate, Bis-EMA: Ethoxylated bisphenol-A dimethacrylate }\end{array}$} \\
\hline
\end{tabular}


$37 \%$ OA, and application of $2.5 \%$ sodium HY. For the conditioning procedure, $37 \%$ OA was placed on the specimens, left for $30 \mathrm{~s}$, washed away with water, and the specimens were then air dried for $10 \mathrm{~s}$. For the $2.5 \% \mathrm{NaOCl}$ conditioning procedure, the specimens were rinsed with $5 \mathrm{~mL} \mathrm{NaOCl}$ and air dried for $10 \mathrm{~s}$. Thereafter, bonding procedures were performed on the aged treated composite surfaces using the corresponding bonding agent of the repair composite resin, strictly in accordance with the manufacturer's instructions.

Following the curing of the adhesive, a teflon matrix which manufactured to fit exactly on the aged surface and to specify the exact dimensions of the repair material ( $3 \mathrm{~mm}$ in diameter and $4 \mathrm{~mm}$ in height) was placed over the aged specimen substrates and filled in two increments with the repair composite. Each increment was light-cured for $20 \mathrm{~s}$ using the same LED polymerization device and the bonded specimen was removed from the matrix with slight pressure on the top of the repair composite cylinder. This procedure resulted in cylinders of repair composite measuring $3 \mathrm{~mm}$ in diameter and $4 \mathrm{~mm}$ in height being bonded to the aged resin [Figure 1a]. All bonding procedures were carried out by the same investigator.

In the manner described above, 160 cylinders of repair composite resin specimens comprised of 16 groups of 10 specimens were prepared. The combinations of the materials and surface treatments used are shown in Table 2.

The bonded specimens were subjected to an aging procedure, undergoing storage for 7 days in artificial saliva followed by thermo-cycling (5000 cycles

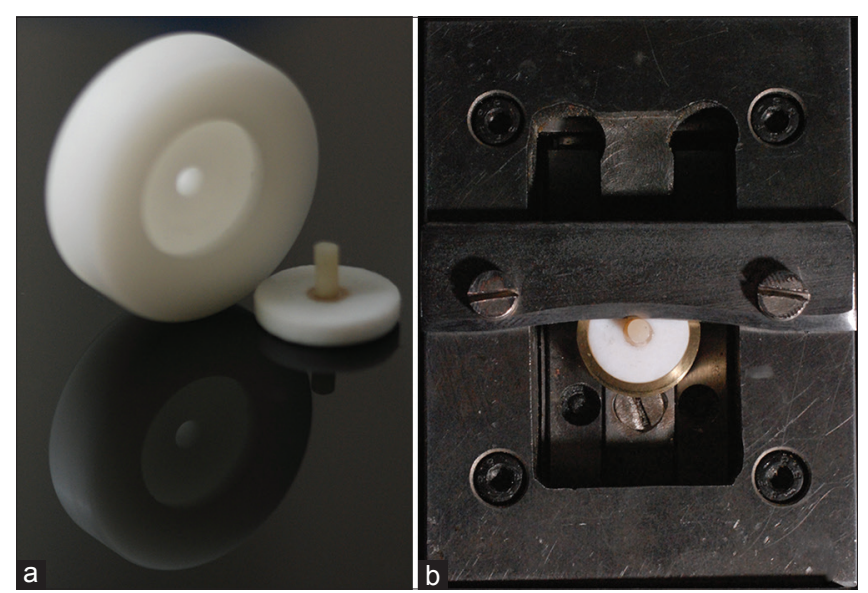

Figure 1: Devices used for conducting the experiment. (a) The teflon matrix that used to form the specimens along with a prepared specimen. (b) The shear device and the specimen positioned in it prior loading between $5^{\circ} \mathrm{C}$ and $55^{\circ} \mathrm{C}$, dwell time $30 \mathrm{~s}$ ). Shear testing was conducted using a universal testing machine (Testometric AX, M 350-10KN, Rochdale, England) at a crosshead speed of $0.5 \mathrm{~mm} / \mathrm{min}$ until fracture. The specimens were fixed on a modified shear fixture, and the load was applied with the use of a chisel [Figure 1b]. The load at fracture, expressed in $\mathrm{MPa}$, was calculated by dividing the peak load by the bonding area, and this value was used in statistical analyses.

The assumption of normality was tested with the Shapiro-Wilk test. Levene's test for equality of error variances was used to test the assumption of homogeneity. According to the results of the above tests, the nonparametric Mann-Whitney U-test was used for comparisons of the interaction between base material and surface treatment. Adjustment for Type I error resulting from multiple tests was achieved via the Bonferroni method. All analyses were performed with IBM Corp. Released 2010. IBM SPSS Statistics for Windows, Version 19.0. Armonk, NY: IBM Corp., and statistical significance was set at $P<0.05$.

Failure patterns at the resin/resin system interface were analyzed under a stereomicroscope (Olympus Co., Tokyo, Japan) at $\times 40$ magnification, to determine the failure modes. Failure was considered to be (a) "adhesive", if it occurred at the resin/

Table 2: Combination of materials and surface treatment procedures. The grey cells represent the pretest failure groups

\begin{tabular}{llll}
$\begin{array}{l}\text { Base } \\
\text { composite }\end{array}$ & $\begin{array}{l}\text { Repair } \\
\text { composite }\end{array}$ & $\begin{array}{l}\text { Surface } \\
\text { treatment }\end{array}$ & $\begin{array}{l}\text { Conditioning } \\
\text { procedures \% }\end{array}$ \\
\hline MC & MC & DB & OA \\
& & HY \\
& AA & OA \\
& & HY \\
& SIL & OA & HY \\
& & OA \\
& & AA & HY \\
& & OA \\
SIL & DB & HY \\
& MC & OA \\
& & AA & HY \\
& & OA \\
& SIL & DB & OA \\
& & HA \\
& & & AA
\end{tabular}

OA: Orthophosphoric acid $37 \%$, HY: Sodium Hypochlorite $2.5 \%$, AA: Air abrasion, DB: Diamond bur, SIL: Silorane matrix composite, MC: Methacrylate matrix composite 
adhesive interface, (b) "cohesive", if it occurred in aged composite or in new composite, and (c) "mixed", when both the interface and the composite were involved. The bond failure patterns were not statistically analyzed. Three specimens from each group that were tested for shear bond strength were randomly selected for evaluation using scanning electron microscopy (SEM, Joel, J.S.M. - 840 Tokyo, Japan). The specimens were mounted on stubs, sputter-coated with carbon and examined by one evaluator under SEM at $19 \mathrm{KV}$.

\section{RESULTS}

Initial repair was not possible for some groups and resulted in many pretest failures, particularly for aged MC with the application of SIL using the SIL adhesive. Failure was observed for all kinds of surface treatment tested. Table 2 shows the pretest failure groups and groups with successful bonds. The pretest failures were not statistically analyzed. Higher bond strength values were achieved when aged $\mathrm{MC}$ was repaired with the application of new MC with DB grinding, conditioning with $\mathrm{OA}$, and Single Bond Adhesive was used as the bonding agent $(69.93 \pm 13.98 \mathrm{MPa})$. In contrast, lower bond strength values were evident when aged SIL was repaired with new MC with DB grinding, conditioning with $\mathrm{OA}$, and bonding with Single Bond Adhesive (25.97 $\pm 8.67 \mathrm{MPa})$ [Figure 2]. When comparing base composite resins, ignoring all other factors (surface treatment), statistically significant differences were observed in bond strength between MC and SIL (Mann-Whitney U-test, $P<0.001)$.

When comparing grinding procedure surface treatments, ignoring all other factors, nonstatistically significant differences were observed between DB and AA (Mann-Whitney U-test, $P=0.761$ ). In addition, no statistically significant differences were observed between $\mathrm{OA}$ and sodium HY when conditioning procedures were compared, ignoring all other factors (Mann-Whitney U-test, $P=0.499$ ).

No statistically significant differences were observed when comparing the interaction between surface treatments (Mann-Whitney U-test with Bonferroni adjustment, $P>0.05)$, ignoring all other factors. Collectively, the above results indicate that the combination of composite based materials (MC-based composite and SIL-based composite) used is the most significant factor influencing the bond strength in this experimental context, as none of the other factors had a significant influence on the bond quality of the repaired composite resins.

No statistically significant differences were observed between any combination of surface treatments when $\mathrm{MC}$ was used as the base resin (Mann-Whitney U-test with Bonferroni adjustment, $P>0.05$ ).

When the base resin was SIL, statistically significant differences (Mann-Whitney U-test with Bonferroni adjustment) were observed between $\mathrm{DB}+\mathrm{OA}$ and $\mathrm{DB}+\mathrm{HY}(P=0.012)$, and $\mathrm{DB}+\mathrm{OA}$ and $\mathrm{AA}+\mathrm{OA}(P=0.012)$, while no other comparisons yielded statistically significant differences $(P>0.05)$.

Table 3 shows the failure mode results of the specimens that were analyzed under a stereomicroscope after shear bond tests. In almost all groups, most fracture modes were mixed, but in the SIL-SIL-DB-OA group, most were adhesive.

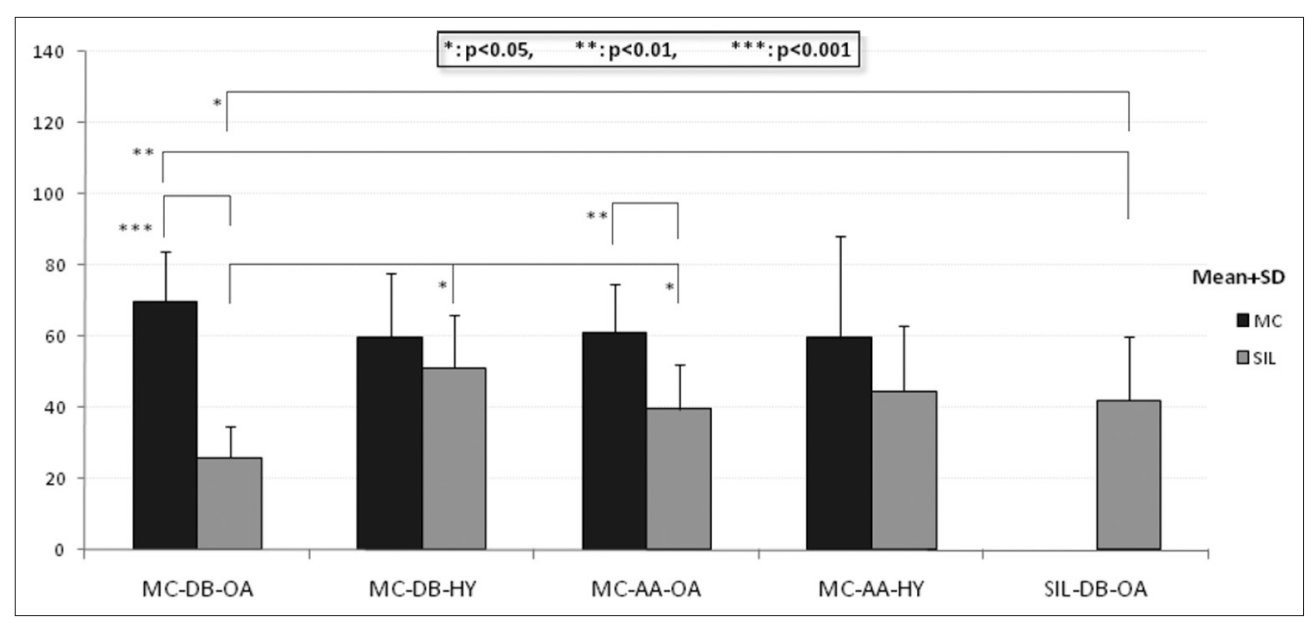

Figure 2: Shear bond strength of repair composite resins 


\section{DISCUSSION}

The first hypothesis that composites with different organic matrix compositions demonstrate the same reparability has to be rejected since at this study composites with different matrix compositions demonstrated repair bond strength variations.

This study shows that MC-based composite can be repaired with a MC-based composite and the corresponding bonding agent, and adequate bonding could be achieved in every combination of surface treatment that was investigated in this study [Figure 3a and b]. Conversely, MC-based composite could not be effectively repaired with SIL-based composite and the corresponding bonding agent, since no combination of surface treatment investigated in this study established an adequate bond.

Artificial aging of MC-based composites creates degradation processes which cause increased water sorption. ${ }^{[4]}$ Owing to their hydrophobic siloxane component, SIL-based composites are more

\begin{tabular}{|c|c|c|c|}
\hline \multicolumn{4}{|l|}{ Failure mode } \\
\hline Group & Adhesive (\%) & Cohesive (\%) & Mixed (\%) \\
\hline MC-MC-DB-OA & $2(20)$ & $1(10)$ & $7(70)$ \\
\hline MC-MC-DB-HY & $3(30)$ & $1(10)$ & $6(60)$ \\
\hline MC-MC-AA-OA & $4(40)$ & $1(10)$ & $5(50)$ \\
\hline MC-MC-AA-HY & $3(30)$ & $1(10)$ & $6(60)$ \\
\hline SIL-MC-DB-OA & $5(50)$ & $1(10)$ & $4(40)$ \\
\hline SIL-MC-DB-HY & $4(40)$ & $0(0)$ & $6(60)$ \\
\hline SIL-MC-AA-OA & $4(40)$ & $1(10)$ & $5(50)$ \\
\hline SIL-MC-AA-HY & $3(30)$ & $0(0)$ & $7(70)$ \\
\hline SIL-SIL-DB-OA & $7(70)$ & $1(10)$ & $2(20)$ \\
\hline
\end{tabular}

OA: Orthophosphoric acid 37\%, HY: Sodium Hypochlorite 2.5\%, AA: Air abrasion, DB: Diamond bur, SIL: Silorane matrix composite, MC: Methacrylate matrix composite
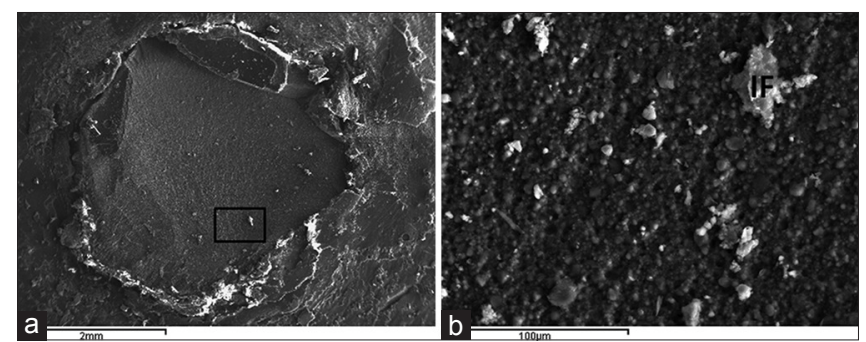

Figure 3: Scanning electron microscopy images of a specimen where aged methacrylate (MC) has been repaired with $\mathrm{MC}$ after the aged surface was treated with air abrasion and conditioned with orthophosphoric acid. (a) Adhesive failure with mixed components. The area marked inside the square is the magnified area in " $b$ " $(\times 20)$. (b) Detailed view of the fractured area. Inorganic fillers originating on the repair resin are detectable on the aged resin surface $(\times 500)$ hydrophobic than MC-based composites. ${ }^{[26]}$ This may influence the reparability of MC-based composites with SIL-based composite and the corresponding bonding agent.

In contrast, SIL-based composite could be effectively repaired with SIL- and MC-based composite and the corresponding bonding agent [Figure $4 \mathrm{a}$ and $\mathrm{b}$ ]. SIL-based composite is more resistant to water sorption and disintegration, and this leads to smaller changes in material properties resulting from aging. ${ }^{[4,27]}$ SIL-based composite could only be used effectively as a repair composite for aged SIL with the surface treatment combination of DB and OA. Although, the poor shear bond strength results along with the high rate of adhesive failures that the failure mode analysis showed for this group are evidence of the weakness of bonding in this context. This result is concordant with a study reported by Ivanovas et al., ${ }^{[15]}$ who concluded that SIL-based composite can be effectively repaired with MC-based composite. The results of this study show that the $\mathrm{MC}$ resins that were repaired with the same composite reached the highest possible bond strength. The failure pattern analysis affirms the above results, as a large number of mixed and cohesive fractures were observed.

The reparability of MC-based composite and SIL-based composite differs depending on whether the material is used as a base material or as a repair material. MC-based composite yielded good results when used as a base material, as well as a repair material. In contrast, SIL-based composite yielded good results when used as a base material, but was evidently a poor repair material. These results are concordant with those of a study reported by Baur and Ilie ${ }^{[22]}$ who concluded that the properties of materials can differ strongly depending on whether they are used as a base material, or a repair material.

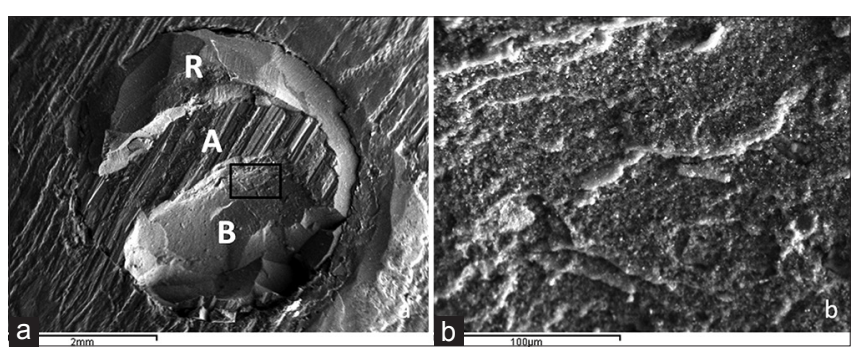

Figure 4: Scanning electron microscopy images of a specimen where aged silorane was repaired with methacrylate after the aged surface was treated with diamond bur and conditioned with hypochlorite. (a) Mixed fracture. Distinguishable are the repair composite (R), the adhesive failure area $(\mathrm{A})$ and the base composite (B). The area marked inside the square is the magnified area in " $b$ " $(\times 20)$. (b) Magnification of the failure line in the base composite area $(\times 500)$ 
Some sources ${ }^{[11,12,15,17,20]}$ propose the additional use of silane as an intermediate agent, in order to effectively repair a SIL-based composite. On the contrary a new research on microtensile bond strength of SIL-based composites repaired with MC-based composites showed that silane did not contributed to an increase in the tensile strength. ${ }^{[24]}$ In this study, a silane solution was not employed prior to the adhesive, in order to focus on the influence of grinding and conditioning of the repair surface on the bond. Implementation of silane enhances the wetting of the surface for the bonding agent, which then infiltrates easily into the irregularities created by the surface roughening. ${ }^{[10,11,20]}$ and the silane-coated composite surface becomes more reactive to the $\mathrm{MC}$ groups of the repair resin.

With regard to surface treatment, it should be noted that both DB and AA procedures are used to increase the micromechanical retention of the new material onto the aged composite. In this study, there were no statistically significant differences between the two grinding procedures tested. These results are concordant with the results of Rathke et al. ${ }^{[28]}$ and Yesilyurt et al., ${ }^{[29]}$ who investigated the influence of different methods of mechanical roughening on bond quality between new and aged composite.

A treated composite either with $\mathrm{DB}$ or with AA infiltrates on its surface organic and inorganic particles originated on the environment. The conditioning procedure using OA does not aim to decalcification of the resin surface similar with what happens in the hard dental tissues surfaces. It is used is an order to obtain a cleansing effect by removing inorganic particles. On the contrary, sodium HY is a known organic solvent, which is used in many dental applications in order to remove the organic particles from surfaces. ${ }^{[30]}$ Statistical analysis in this study has shown that there were no statistically significant differences between the two types of conditioning procedures.

The statistical analysis of the results of this study showed that the best two combinations of surface treatment were DB with OA, and AA with OA.

Therefore, the second hypothesis should be rejected up to a point, and it is concluded that within the limitations of this study the surface treatment has a minor influence on the shear bond strength of repaired composites. This is concordant with Loomans et al., ${ }^{[13]}$ who attested that none of the common surface treatments can be recommended as a universally applicable repair technique, since their effectiveness is material-dependent.
The authors are in agreement with the conclusions of a recent systematic review that repair of restorations is a valuable method of improving their quality, and can yield acceptable results. However, methodologically sound, randomized, controlled, long-term clinical trials are required, in order to facilitate evidence-based recommendations. ${ }^{[31]}$

\section{CONCLUSIONS}

Within the limitations of this study, it can be concluded that:

I. Material is the major contributory factor for the successful repair of a composite resin restoration.

II. Knowing the composition of the aged composite should allow the operator to achieve reliable bond strength with the new composite resin.

III. MC-based composites showed better reparability than SIL-based composites.

IV. Regarding the surface treatment, no statistical differences in repair bond strength were evident.

\section{REFERENCES}

1. Manhart J, Chen H, Hamm G, Hickel R. Buonocore Memorial Lecture. Review of the clinical survival of direct and indirect restorations in posterior teeth of the permanent dentition. Oper Dent 2004;29:481-508.

2. Christensen GJ. When and how to repair a failing restoration. J Am Dent Assoc 2007;138:1605-7.

3. Gordan VV, Garvan CW, Blaser PK, Mondragon E, Mjör IA. A long-term evaluation of alternative treatments to replacement of resin-based composite restorations: Results of a seven-year study. J Am Dent Assoc 2009;140:1476-84.

4. Mjör IA, Gordan VV. Failure, repair, refurbishing and longevity of restorations. Oper Dent 2002;27:528-34.

5. Sharif MO, Fedorowicz Z, Tickle M, Brunton PA. Repair or replacement of restorations: Do we accept built in obsolescence or do we improve the evidence? Br Dent J 2010;209:171-4.

6. Swift EJ Jr, LeValley BD, Boyer DB. Evaluation of new methods for composite repair. Dent Mater 1992;8:362-5.

7. Kukiattrakoon B, Thammasitboon K. Optimal acidulated phosphate fluoride gel etching time for surface treatment of feldspathic porcelain: On shear bond strength to resin composite. Eur J Dent 2012;6:63-9.

8. Zaghloul H, Elkassas DW, Haridy MF. Effect of incorporation of silane in the bonding agent on the repair potential of machinable esthetic blocks. Eur J Dent 2014;8:44-52.

9. Rodrigues SA Jr, Ferracane JL, Della Bona A. Influence of surface treatments on the bond strength of repaired resin composite restorative materials. Dent Mater 2009;25:442-51.

10. Celik EU, Ergücü Z, Türkün LS, Ercan UK. Tensile bond strength of an aged resin composite repaired with different protocols. J Adhes Dent 2011;13:359-66.

11. Hamano N, Chiang YC, Nyamaa I, Yamaguchi H, Ino S, Hickel R, et al. Effect of different surface treatments on the repair strength of a nanofilled resin-based composite. Dent Mater J 2011;30:537-45.

12. Rinastiti M, Özcan M, Siswomihardjo W, Busscher HJ. Effects of surface conditioning on repair bond strengths of non-aged and aged microhybrid, nanohybrid, and nanofilled composite resins. Clin Oral Investig 2011;15:625-33.

13. Loomans BA, Cardoso MV, Roeters FJ, Opdam NJ, De Munck J, Huysmans MC, et al. Is there one optimal repair technique for all composites? Dent Mater 2011;27:701-9.

14. Özcan M, Corazza PH, Marocho SM, Barbosa SH, Bottino MA. Repair bond strength of microhybrid, nanohybrid and nanofilled resin 
composites: Effect of substrate resin type, surface conditioning and ageing. Clin Oral Investig 2013;17:1751-8.

15. Ivanovas $S$, Hickel R, Ilie N. How to repair fillings made by silorane-based composites. Clin Oral Investig 2011;15:915-22.

16. Ilie N, Hickel R. Macro-, micro- and nano-mechanical investigations on silorane and methacrylate-based composites. Dent Mater 2009;25:810-9.

17. Lührs AK, Görmann B, Jacker-Guhr S, Geurtsen W. Repairability of dental siloranes in vitro. Dent Mater 2011;27:144-9.

18. Popoff DA, Santa Rosa TT, Ferreira RC, Magalhães CS, Moreira AN, Mjör IA. Repair of dimethacrylate-based composite restorations by a silorane-based composite: A one-year randomized clinical trial. Oper Dent 2012;37:E1-10.

19. Lima AF, Ferreira SF, Catelan A, Palialol AR, Gonçalves LS, Aguiar FH, et al. The effect of surface treatment and bonding procedures on the bond strength of silorane composite repairs. Acta Odontol Scand 2014;72:71-5.

20. Maneenut C, Sakoolnamarka R, Tyas MJ. The repair potential of resin composite materials. Dent Mater 2011;27:e20-7.

21. Giachetti L, Scaminaci Russo D, Baldini M, Goracci C, Ferrari M. Reparability of aged silorane with methacrylate-based resin composite: Micro-shear bond strength and scanning electron microscopy evaluation. Oper Dent 2012;37:28-36.

22. Baur V, Ilie N. Repair of dental resin-based composites. Clin Oral Investig 2013;17:601-8.

23. Bacchi A, Consani RL, Sinhoreti MA, Feitosa VP, Cavalcante LM, Pfeifer CS, et al. Repair bond strength in aged methacrylate- and silorane-based composites. J Adhes Dent 2013;15:447-52.

24. Hamano N, Ino S, Fukuyama T, Hickel R, Kunzelmann KH. Repair of silorane-based composites: Microtensile bond strength of silorane-based composites repaired with methacrylate-based composites. Dent Mater J 2013;32:695-701.
25. Donmez N, Belli S, Pashley DH, Tay FR. Ultrastructural correlates of in vivo/in vitro bond degradation in self-etch adhesives. J Dent Res 2005;84:355-9.

26. Palin WM, Fleming GJ, Burke FJ, Marquis PM, Randall RC. The influence of short and medium-term water immersion on the hydrolytic stability of novel low-shrink dental composites. Dent Mater 2005;21:852-63.

27. Weinmann W, Thalacker C, Guggenberger R. Siloranes in dental composites. Dent Mater 2005;21:68-74.

28. Rathke A, Tymina Y, Haller B. Effect of different surface treatments on the composite-composite repair bond strength. Clin Oral Investig 2009;13:317-23.

29. Yesilyurt C, Kusgoz A, Bayram M, Ulker M. Initial repair bond strength of a nano-filled hybrid resin: Effect of surface treatments and bonding agents. J Esthet Restor Dent 2009;21:251-60.

30. Erhardt MC, Osorio E, Aguilera FS, Proença JP, Osorio R, Toledano M. Influence of dentin acid-etching and $\mathrm{NaOCl}$-treatment on bond strengths of self-etch adhesives. Am J Dent 2008;21:44-8.

31. Hickel R, Brüshaver K, Ilie N. Repair of restorations - Criteria for decision making and clinical recommendations. Dent Mater 2013;29:28-50.

\begin{tabular}{|l|l|}
\hline \multicolumn{2}{|c|}{ Access this article online } \\
\hline Quick Response Code: & Website: \\
\hline & www.eurjdent.com \\
\cline { 2 - 3 } & \\
\hline
\end{tabular}

